\title{
Single-Stage Double-Buck Topologies with High Power Factor
}

\author{
Vitor Fernão Pires ${ }^{\dagger *}$ and José Fernando Silva ${ }^{*, * *}$ \\ ${ }^{\dagger}$ ESTSetúbal-Polytechnic Institute of Setúbal/DEE, Setúbal, Portugal \\ ${ }^{*}$ Center for Innovation in Electrical and Energy Engineering (CIEEE), Lisbon, Portugal \\ ** Instituto Superior Técnico-Technical University of Lisbon/DEEC, Lisbon, Portugal
}

\begin{abstract}
This paper presents two topologies for single-stage single-phase double-buck type PFC converters, designed to operate at high power factor, near sinusoidal input currents and adjustable output voltage. Unlike the known buck type PFC topologies, in which the output voltage is always lower than the maximum input voltage, the proposed converters can operate at output voltages higher than the ac input peak voltage. A reduced number of switches on the main path of the current are another characteristic of the two proposed topologies. To shape the input line currents, a fast and robust controller based on a sliding mode approach is proposed. This active non-linear control strategy, applied to these converters allows high quality input currents. A Proportional Integral (PI) controller is adopted to regulate the output voltage of the converters. This external voltage controller modulates the amplitude of the sinusoidal input current references. The performances of the presented rectifiers are verified with experimental results.
\end{abstract}

Key Words: High power factor, Buck rectifier, Single-phase, Sliding mode controller, Power converter

\section{INTRODUCTION}

The use of industrial and consumer electronic equipment with ac to dc high- frequency switching converters as power supplies has significantly increased in the last few years. Line frequency switched ac to dc power supplies feature simple diode rectifiers needing large dc link capacitors. Diode rectifiers present high harmonic content in the input currents, leading to low input power factor and causing line voltage harmonics and transient disturbances [1], [2]. Therefore, to reduce the impact of the harmonic current injection on the ac network, new standards such as IEEE-519 and IEC 61000-3 have emerged.

To comply with the new standards, high frequency switching mode ac/dc converters with pulse-width modulation (PWM) have been developed. The input current modulation process enables high power factor and minimum harmonic distortion, thus obtaining high quality input currents (close to sinusoidal waveforms) with near unity input power factor. The dominant design of the PWM ac/dc converters, known as power factor correctors (PFC), is the Boost type [3]-[6]. This voltagesource ac-dc converter, which can also be used as inverter, has an ac input filter. As a step-up converter it presents a dc

\footnotetext{
Manuscript received Feb. 15, 2011; revised Jul. 18, 2011

Recommended for publication by Associate Editor Yong-Chae Jung.

$\dagger$ Corresponding Author: vitor.pires@estsetubal.ips.pt

Tel: +351-2657-90000, ESTSetúbal-Polytechnic Institute of Setúbal/DEE, CIEEE

* Center for Innovation in Electrical and Energy Engineering (CIEEE), Portugal

** Instituto Superior Técnico-Technical University of Lisbon/DEEC, Portugal
}

output voltage higher than the ac voltage peak voltage value. Output voltages lower than this value can only be obtained using additional converters or transformers, when using a PFC boost converter. Another disadvantage of the boost type is their inability to limit the switch -on inrush current or the dc-shortcircuit current.

Unlike the boost type ac-dc PFC converter, the buck type PFC has the capability to limit the inrush and de short-circuit currents, but has step-down characteristics, since the output voltage of the rectifier is always lower than the peak voltage value of the input ac sources [7]-[10]. The step-down action can prevent the use of the buck design in some applications. Another disadvantage of buck type PFC design, when compared to the Boost type PFC, is the low efficiency since they usually have a high number of power semiconductors in the ac input current path.

To contribute in overcoming these drawbacks, section II of this paper presents two topologies for single-stage single-phase buck type PFC converter in which the output voltage can be extended beyond the ac input-voltage peak value. Additionally, it is possible to improve the efficiency of these double buck rectifiers, since the number of power semiconductors in the input current path has been reduced. The double buck rectifier operation is presented in section III. The control method (section IV) for the proposed Buck-type ac-dc converter uses a cascade structure. For the inner loop, an input current controller based on a sliding mode approach is proposed. The external voltage control loop includes a proportional plus integral (PI) compensator. To provide near sinusoidal input 


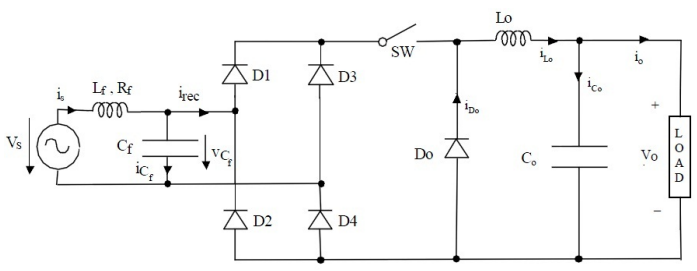

(a) With one turn-off switch.

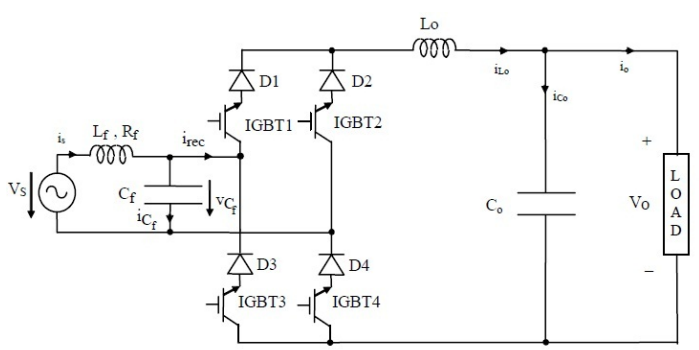

(b) With four turn-off switches.

Fig. 1. Typical single-phase Buck type ac-dc converter topologies.

currents, the external loop voltage controller output is the reference amplitude of the sinusoidal current which is the reference of the inner current mode loop. Experimental results from an experimental laboratory set up are presented and discussed (section V).

\section{Converter Topologies}

Typical single-phase buck type ac-dc converter topologies (Fig. 1) use one turn-off capability switching device and 5 diodes, or four turn-off capability switching devices, such as reverse blocking IGBT, and 4 diodes if the turn-off devices have no reverse voltage capability. The topology from Fig. 1(a) is the simplest, since only one switching device with turn-off capability is used. However, the topology with four turn-off switches (Fig. 1(b)) can be considered advantageous, since the waveform of the ac current has less harmonic distortion, due to the possibility to operate with negative bridge voltages, and the efficiency can be improved if reverse blocking capability turn-off switches are used.

To extend the output voltage range and to reduce the number of turn-off power semiconductors in the input current path, two new topologies, presented in Fig. 2 are proposed. These converters also use an ac filter, four (or two) turnoff switches with bipolar voltage blocking capability, two magnetically coupled inductors and two output capacitors. The two topologies, here termed double buck rectifiers, can limit the inrush and short circuit currents and can present output voltages higher than the ac supply peak value (theoretically limited at two times the peak value, since they are based on two bi-phase converters, each one limited to the ac peak voltage value).

\section{Double Buck Rectifier Operation}

The operating stages of the double buck rectifier presented in Fig. 2(a) during the positive half cycle of the ac source voltage are described below:

$1^{\text {st }}$ Stage (Fig. 3): Switch IGBT1 is turned on and inductor $\mathrm{L}_{\mathrm{o} 1}$ stores energy supplied by the ac source voltage. Therefore,

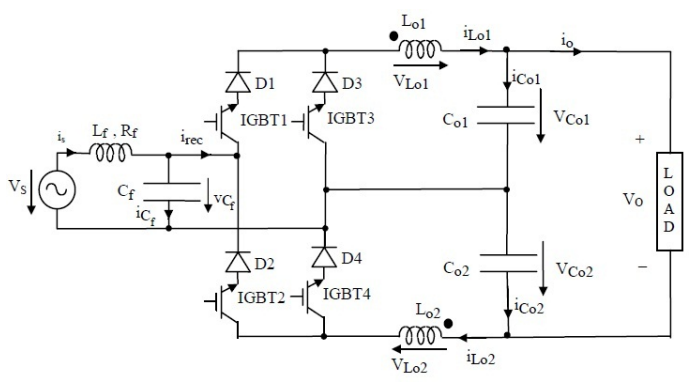

(a) With four turn-off switches.

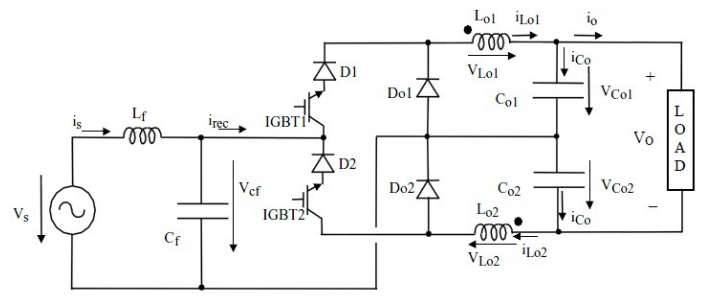

(b) With only two turn-off switches.

Fig. 2. Proposed single-phase Buck type ac-dc converter topologies.

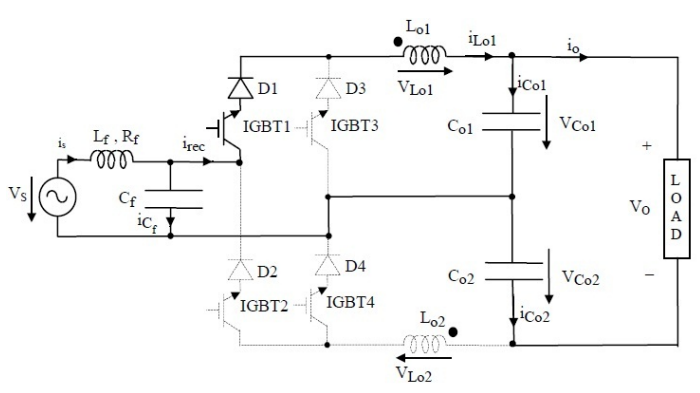

Fig. 3. First stage topologies.

the current in inductor $\mathrm{L}_{\mathrm{o} 1}$ will increase, and if this current is greater than current in inductor $\mathrm{L}_{\mathrm{f}}$, the voltage in capacitor $\mathrm{C}_{\mathrm{f}}$ will decrease and current in inductor $\mathrm{L}_{\mathrm{f}}$ will increase.

$2^{\text {nd }}$ Stage (Fig. 4): Switch IGBT1 is turned off while switches IGBT3 and IGBT4 are turned on. In this stage there are three different possibilities. If voltage $\mathrm{V}_{\mathrm{Co}}$ is higher than $\mathrm{V}_{\mathrm{Co} 2}$, then diode D4 is on and diode D3 is off (Fig. 4(a)). If voltage $\mathrm{V}_{\mathrm{Co} 1}$ is lower than $\mathrm{V}_{\mathrm{Co} 2}$, then diode $\mathrm{D} 3$ is on and diode D4 is off (Fig. 4(b)). If voltages $\mathrm{V}_{\mathrm{Co} 1}$ and $\mathrm{V}_{\mathrm{Co} 2}$ are equal then both diodes are on (Fig. 4(c)). In $1^{\text {st }}$ stage, normally capacitor $\mathrm{C}_{01}$ is charged while capacitor $\mathrm{C}_{02}$ is discharged. Due to this, in this stage the energy stored in inductor $\mathrm{L}_{01}$ is transferred to inductor $\mathrm{L}_{\mathrm{o} 2}\left(\mathrm{~L}_{\mathrm{o} 1}\right.$ is magnetically coupled with $\left.\mathrm{L}_{\mathrm{o} 2}\right)$ and to the capacitor $\mathrm{C}_{\mathrm{o} 2}$ trough switch IGBT4. Diode D3 is turned off. The voltage in capacitor $\mathrm{C}_{\mathrm{f}}$ will increase and current in inductor $\mathrm{L}_{\mathrm{f}}$ will decrease. On other hand, capacitor $\mathrm{C}_{\mathrm{o} 2}$ will charge (relatively to $\mathrm{C}_{\mathrm{o} 1}$ ). When the voltage in capacitor $\mathrm{C}_{\mathrm{o} 2}$ equals the voltage in capacitor $\mathrm{C}_{\mathrm{o} 1}$, diode D3 turns on. Half of the stored energy in inductor $\mathrm{L}_{\mathrm{O} 2}$ is transferred to inductor $\mathrm{L}_{\mathrm{o} 1}$ and to capacitors $\mathrm{C}_{\mathrm{o} 1}$ and $\mathrm{C}_{\mathrm{o} 2}$ trough switches IGBT3 and IGBT4. The voltage in capacitor $\mathrm{C}_{\mathrm{f}}$ will increase and current in inductor $\mathrm{L}_{\mathrm{f}}$ will decrease.

Fig. 5 and 6 show the current waveforms $i_{\text {Lo1 }}$ and $i_{\text {Lo2 }}$. From these figures it is possible to verify the $1^{\text {st }}$ and $2^{\text {nd }}$ stage operation. It is also possible to verify the discontinuity in the DC inductors current due to the magnetic coupling between 


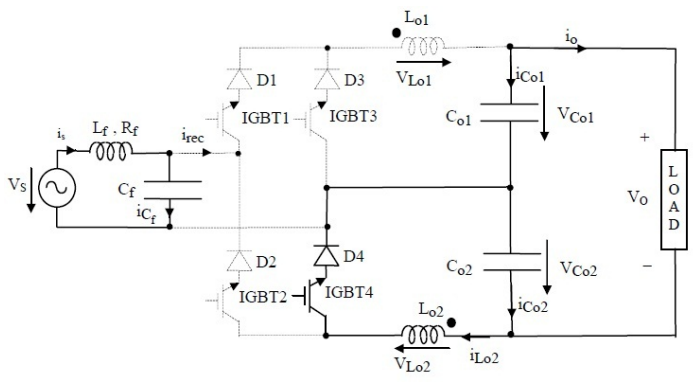

(a) Voltage $V_{C o 1}$ is higher than $V_{C o 2}$.

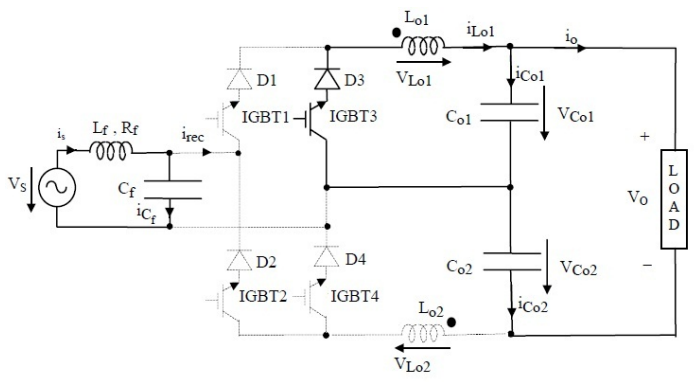

(b) Voltage $\mathrm{V}_{\mathrm{Co1}}$ is lower than $\mathrm{V}_{\mathrm{C} \text { 2 }}$.

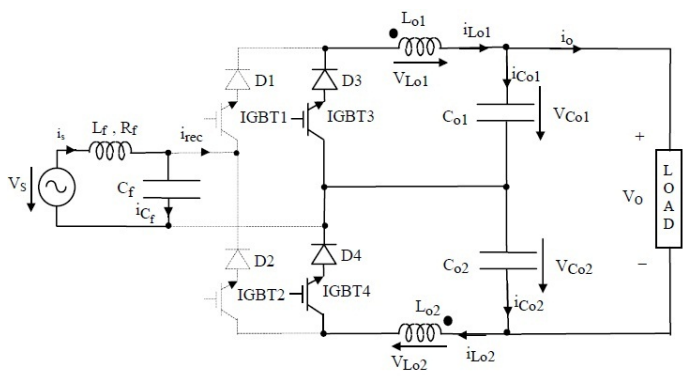

(c) Voltages $V_{\mathrm{Co} 1}$ and $\mathrm{V}_{\mathrm{Co} 2}$ are equal.

Fig. 4. Second stage.

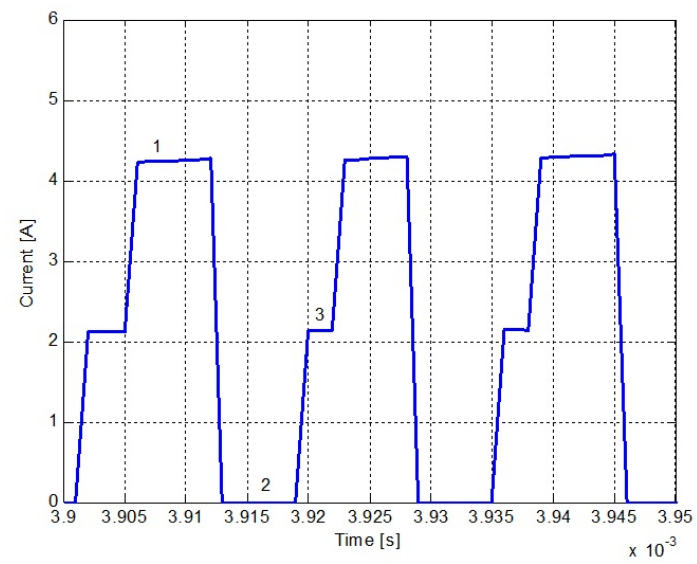

Fig. 5. Inductor current iLo1 (1-1 $1^{\text {st }}$ stage, $2-2^{\text {nd }}$ stage when $V_{C o 1}$ is lower than $\mathrm{V}_{\mathrm{Co} 2}, 3-2^{\text {nd }}$ stage when $\mathrm{V}_{\mathrm{Co} 1}$ is equal to $\mathrm{V}_{\mathrm{Co} 2}$ ).

those inductors. The time zones represented by 1,2 and 3 are related to the stages presented in Fig. 3, 4(a) and 4(c) respectively.

$3^{\text {rd }}$ Stage (Fig. 7): Switch IGBT2 is turned on and the stored energy in inductor $\mathrm{L}_{\mathrm{o} 2}$ is transferred to capacitor $\mathrm{C}_{\mathrm{f}}$. The voltage in capacitor $\mathrm{C}_{\mathrm{f}}$ will increase and current in inductor $\mathrm{L}_{\mathrm{f}}$ will decrease.

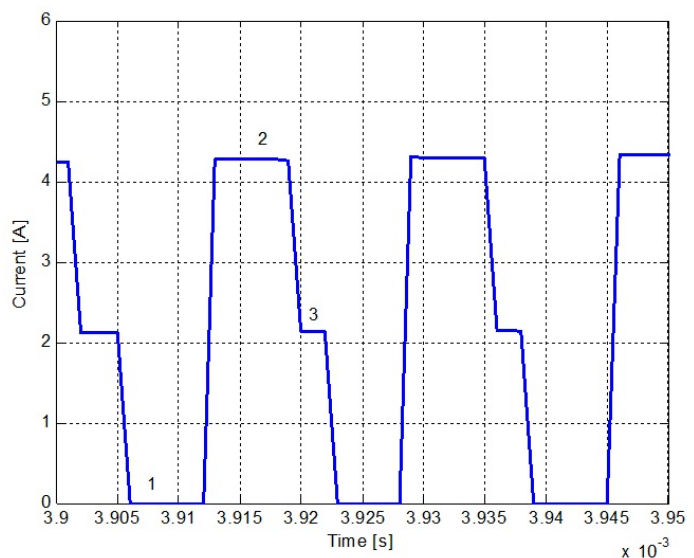

Fig. 6. Inductor current $i_{\text {Lo2 }}\left(1-1^{\text {st }}\right.$ stage, $2-2^{\text {nd }}$ stage when $V_{\mathrm{Co} 1}$ is lower than $\mathrm{V}_{\mathrm{Co} 2}, 3-2^{\text {nd }}$ stage when $\mathrm{V}_{\mathrm{Co} 1}$ is equal to $\mathrm{V}_{\mathrm{Co} 2}$ ).

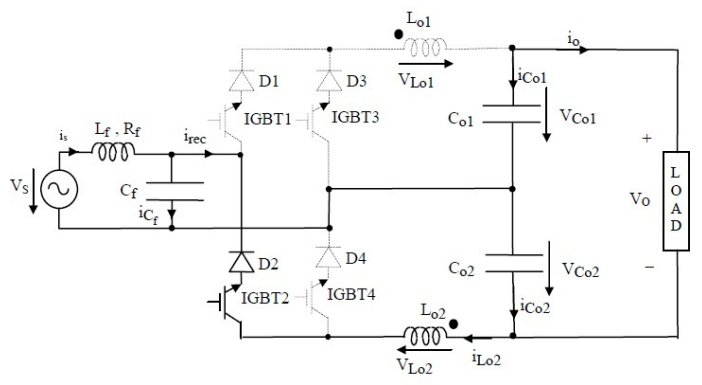

Fig. 7. Third stage.

In the negative half cycle of the ac source voltage there are also three operating stages. However, in the first stage IGBT2 is turned on, instead of IGBT1. In the third stage IGBT1 is turned on.

For the double buck rectifier presented in Fig. 2(b), the operation stages in the positive half cycle of the ac source voltage can also be described by the same three stages. However, while the input voltage capacitor $\mathrm{C}_{\mathrm{f}}$ is positive the IGBT2 cannot be turned on, the main stages being only the $1^{\text {st }}$ and $2^{\text {nd }}$ stages. For the negative half cycle, since the input voltage capacitor is normally negative, then diode D1 is reverse biased. In this way, the main stages are only the $2^{\text {nd }}$ and $3^{\text {rd }}$ stages.

\section{Control of the Double Buck Rectifier}

In PWM rectifiers, the input ac current dynamics usually must be much faster than the dc output voltage dynamics. Then, it is straightforward to separate the dynamics of the ac input current from the dynamics of the dc output voltage, allowing the use of a cascaded control structure. Therefore, to provide sinusoidal input current, the reference of the inner current loop must be nearly sinusoidal in phase with the input line voltage. Its sinusoidal amplitude will be defined by the voltage controller external loop (Fig. 8). As the ac input current $\left(\mathrm{i}_{\text {rec }}\right)$ of the double-buck switch-mode rectifier is controlled using on-off switches, the use of sliding-mode approach is advantageous, because sliding-mode controllers easily generate the needed discontinuous control actions and can ensure stability, robustness concerning system parameters and non modeling dynamics [11]-[16], being advantageous over constant frequency current mode control. 


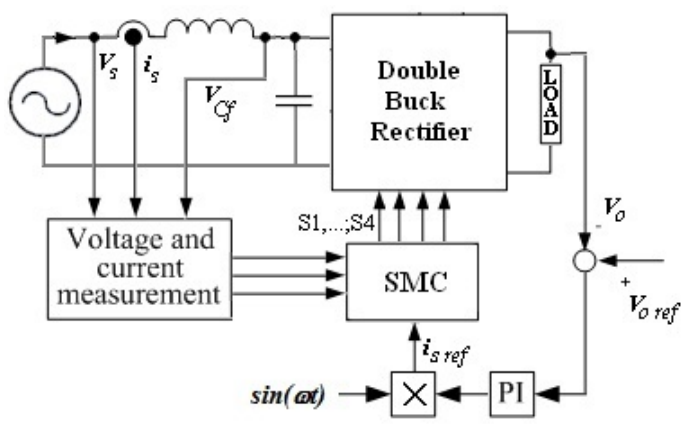

Fig. 8. Control structure of the double-buck rectifier.

Since the dynamics of this converter can be divided into fast motion (input ac current) and slow motion (output dc voltage), the output voltage control of this circuit can be controlled using a PI compensator, with gains selected to provide a stable system with good enough steady-state and dynamic responses.

\section{A. Input current controller}

The design method [11]-[15] for the proposed sliding mode current controller consists of two major parts: the design of the sliding surface and the design of the stable and robust switching control law that drives the state of the system towards the sliding surface. From the double-buck rectifier state-space model (1), it can be seen that the active switches only indirectly control the input line current $\left(i_{s}\right)$.

$$
\left\{\begin{array}{l}
\frac{d i_{s}}{d t}=-\frac{R_{f}}{L_{f}} i_{s}-\frac{1}{L_{f}} v_{C_{f}}+\frac{1}{L_{f}} v_{s} \\
\frac{d v_{C_{f}}}{d t}=\frac{1}{C_{f}} i_{s}-\frac{\alpha_{1}}{C_{f}} i_{L_{o 1}}+\frac{\alpha_{2}}{C_{f}} i_{L_{o 2}} \\
\frac{d \psi_{o}}{d t}=\left(\alpha_{1}-\alpha_{2}\right) v_{C_{f}}-\alpha_{3} v_{C_{o 1}}-\alpha_{4} v_{C_{o 2}} \\
\frac{d v_{C_{o 1}}}{d t}=i_{L_{o 1}}-\frac{1}{R_{o} C_{o}} V_{o} \\
\frac{d v_{C_{o 2}}}{d t}=i_{L_{o 2}}-\frac{1}{R_{o} C_{o}} V_{o}
\end{array} .\right.
$$

The variables $a_{1}$ to $a_{4}$ represent respectively the states of the IGBT 1 to 4 (for the topology presented in Fig. 2(a) and variables $a_{3}$ and $a_{4}$ represent respectively the states of the diodes Do1 and Do2 for topology presented in Fig. 2(b) (2).

$$
\alpha_{i}=\left\{\begin{array}{ll}
1 & , \text { Switch } i \text { is on } \\
0 & , \text { Switch } i \text { is off }
\end{array} \quad, \quad i=1,2,3,4 .\right.
$$

Considering the $i_{s}$ current to be the controlled output, the input-output linearization of the state-space model (1), allows the following state-space model in the controllability canonical form:

$$
\frac{d}{d t}\left[\begin{array}{c}
i_{s} \\
\theta
\end{array}\right]=\left[\begin{array}{c}
\theta \\
-\frac{R_{f}}{L_{f}} \theta-\frac{1}{L_{f} C_{f}} i_{s}+\frac{\omega}{L_{f}} V_{s \max } \cos (\omega t)- \\
-\frac{\alpha_{1}}{L_{f} C f} i_{L_{o 1}}-\frac{\alpha_{2}}{L_{f} C f} i_{L_{o 2}}
\end{array}\right]
$$

where,

$$
\theta=\frac{v_{s}-R_{f} i_{s}-v_{C_{f}}}{L_{f}} .
$$

From (3) and (4) it is possible to conclude that the input line current has a strong relative degree of two [11], [13] (since its second time derivative contains the control variables $a_{i}$ ). So, considering this strong relative degree of the output variable $\left(i_{s}\right)$, and the feedback tracking errors as the state variables $\left(e_{i_{s}}=i_{s} r e f-i_{s} ; \quad e_{\theta}=\theta_{r e f}-\theta\right)$, the sliding surface ensuring the robustness of the closed loop system, is:

$$
\begin{aligned}
S\left(e_{i_{s}}, e_{\theta}\right) & =\left(i_{\text {sref }}-i_{s}\right)+k\left(\theta_{\text {ref }}-\theta\right)= \\
& =\left(i_{s r e f}-i_{s}\right)+k\left(\frac{d i_{s} r e f}{d t}-\frac{d i_{s}}{d t}\right)
\end{aligned}
$$

where $k(k>0)$ is a parameter related to the time constant of the desired first order response of the tracking error $\left(i_{s} r e f-i_{s}\right)$.

Using (4) it is obtained

$$
\begin{aligned}
S\left(e_{i_{s}}, e_{\theta}\right) & =\left(i_{\text {sref }}-i_{s}\right)+k \frac{d i_{\text {sref }}}{d t}- \\
& -\frac{k}{L_{f}}\left(v_{s}-R_{f} i_{s}-v_{C_{f}}\right) .
\end{aligned}
$$

\section{B. Switching strategy}

The switching strategy must guarantee that the tracking error $\left(i_{s} r e f-i_{s}\right)$ trajectory moves towards the origin and stays on the sliding surface from any initial condition. This can be accomplished if the switching strategy enforces the following stability condition:

$$
S \quad\left(e_{i_{s}}, e_{\theta}\right) \dot{S} \quad\left(e_{i_{s}}, e_{\theta}\right)<0 .
$$

Since the topology presented in Fig. 2(a) has three operation stages, a three level hysteretic comparator with equivalent hysteresis $\varepsilon$ and $\delta$ (Fig. 9(a)) will be needed to select each one of the 3 stages of the double-buck rectifier, upon the value of $S\left(e_{i_{s}}, e_{\theta}\right)$. Hysteresis widths are chosen to limit the maximum switching frequency.

For the double buck of Fig. 2(a), if the hysteretic comparator output $\alpha$ is -1 then IGBT 1 is turned on (first stage). If $\alpha$ is zero then IGBT's 3 and 4 are turned on (second stage). Finally, if $\alpha$ is +1 then IGBT 2 is turned on (third stage).

For the double-buck of Fig. 2(b), the stability condition (7) can be accomplished using only a two level hysteretic comparator with hysteresis $2 \gamma($ Fig. 9(b)), also dependent on the $S\left(e_{i_{s}}, e_{\theta}\right)$ value. In this case, if $\alpha$ is zero then IGBT 1 is turned on (first stage). If $\alpha$ is +1 then IGBT 2 is driven on (second stage). Although the IGBT 2 gate signal is on, for the positive half cycle of the ac source voltage, the input capacitor voltage is positive and reverse biases the IGBT 2 series diode, so that only Do1 and Do2 can be on (second stage). Therefore, although there are signals to turn on IGBT1 $(\alpha=0)$ and IGBT2 $(\alpha=+1)$, in the positive half cycle only IGBT1 will be in the on state, the converter operating with two stages (first and second stages). Due to symmetry, in the negative half cycle the operating stages will be the second and the third.

\section{Output Voltage Controller}

To control the converter output voltage, given its slower dynamics, a proportional plus integral compensator (PI) is chosen and sized to have a stable system with good steadystate and dynamic responses. As the input frequency of the system is much lower $(50 \mathrm{~Hz}$ or $60 \mathrm{~Hz})$ than the switching 


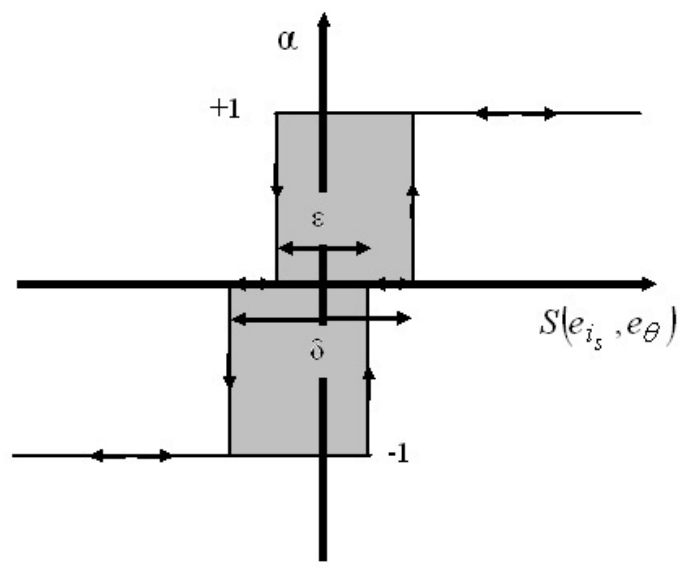

(a) Three level hysteretic comparator.

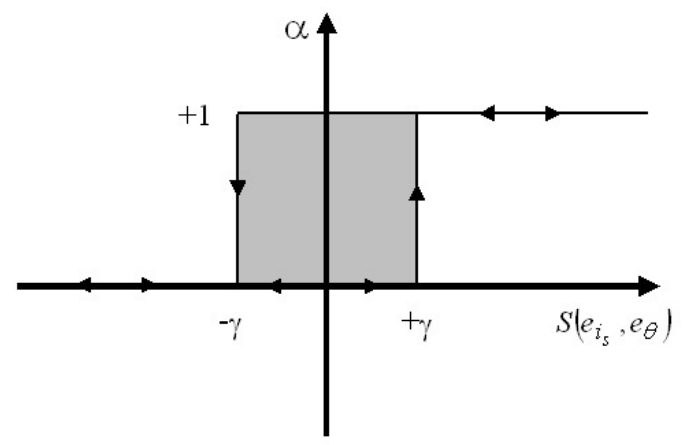

(b) Two level hysteretic comparator.

Fig. 9. Switching strategy for the rectifiers presented in Figs. 2(a) and 2(b).

frequency, an equivalent simplified model is used to determine the values of the PI compensator parameters. This simplified model considers that the sliding mode current controlled rectifier can be considered as a current controlled current source $I / I_{r e f}=K_{I} /\left(1+s T_{d}\right)$ with gain $K_{I}$ and time delay $T_{d}$ $\left(T_{d} \approx \pi / \sqrt{L_{o 1} C_{o 1}}\right)$.

Assuming that the rectifier is conservative, i.e., the input power equals the output power, and near unity input factor the $K_{S}=I_{o} / I_{S M}$ value can be obtained by (8).

$$
K_{S} \approx \frac{V_{s \max }}{2 V_{o}} .
$$

The output voltage $V_{o}$ is controlled by changing the amplitude $I_{S M}$ of the input current. This is done by a linear PI controller (Fig. 8), processing the error between the output voltage reference $V_{\text {oref }}$ and the actual output $V_{o}$. From the closed loop transfer function of the equivalent diagram, a second order transfer function can be obtained. Cancelling the load pole with the PI zero and using $\sqrt{2} / 2$ for the required damping factor of the resulting $2^{\text {nd }}$ order system, equations (9) and (10) can be derived to obtain the $K_{p}$ and $K_{I}$ parameters of the PI controller.

$$
\begin{gathered}
K_{p} \approx \frac{C_{o}}{4 \zeta^{2} T_{d}} \\
K_{i} \approx \frac{1}{4 \zeta^{2} T_{d} R_{o}} .
\end{gathered}
$$

TABLE I

PARAMETERs OF THE TEST SySTEM

\begin{tabular}{|l|l|}
\hline Description & Value \\
\hline Lf & $5 \mathrm{mH}$ \\
\hline Cf & $15 \mathrm{mF}$ \\
\hline Lo1, Lo2 & $1 \mathrm{mH}$ \\
\hline Co1, Co2 & $470 \mathrm{mF}$ \\
\hline Load & $10 \Omega$ \\
\hline
\end{tabular}

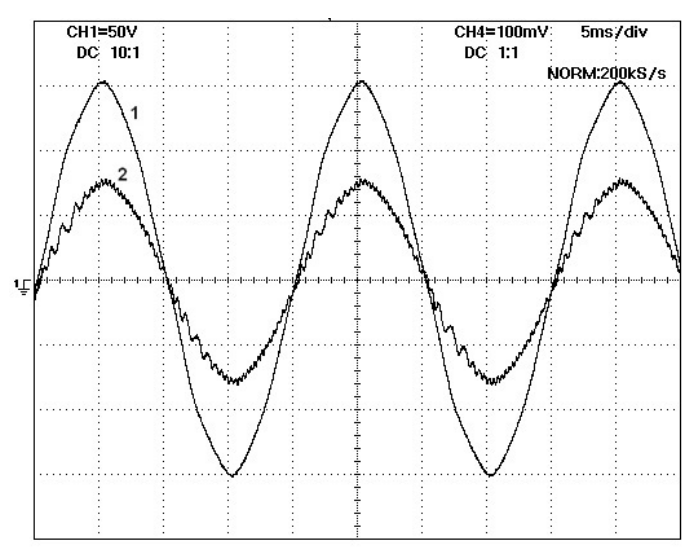

Fig. 10. Experimental result of: 1- input source voltage (50V/Div) and 2 input line current (1A/Div).

\section{EXPERIMENTAL RESUlts}

To verify the operation principles and the control algorithms of the proposed double-buck topology a laboratory prototype was implemented. The parameters of the test system are reported in Table I.

Fig. 10 shows an experimental result of the input voltage and line current for the rectifier presented in Fig. 2(a). From this figure it is possible to confirm that the proposed rectifier provides almost sinusoidal input current and high power factor. The input source current is dominated by the main frequency sinusoid and the switching frequency components are greatly attenuated. The total harmonic distortion (THD) of the input line currents is $3.5 \%$. For the four switch converter the THD is $3.2 \%$. The reason for the THD reduction is due to the fully controlled rectifier, since in each half cycle the input current $i_{\text {rec }}$ can be positive or negative. Fig. 11 shows an experimental result of the dc inductor current $\left(i_{L o 1}\right)$ for the two switches rectifier, where it can be seen the discontinuous mode of operation of this current. This is explained by the magnetic coupling between the dc inductors.

Fig. 12 show the conversion efficiency versus the RMS input line voltage for the circuits with two and four switches. As expected, the efficiency is greater for the converter of the two switches. Increasing the input line voltage the difference of the efficiency of the two converters is reduced.

Fig 13 shows the total harmonic distortion versus RMS input voltage. The harmonic distortion becomes smaller when the input voltage increases. This is a consequence of the small current inside of the dc inductor at the beginning of each half-cycle. When the input voltage increases, the dc inductor current also increases, reducing the distortion at the beginning of each half-cycle. As expected, the THD is smaller for the converter of the four switches.

The power factor characteristics are related with input 


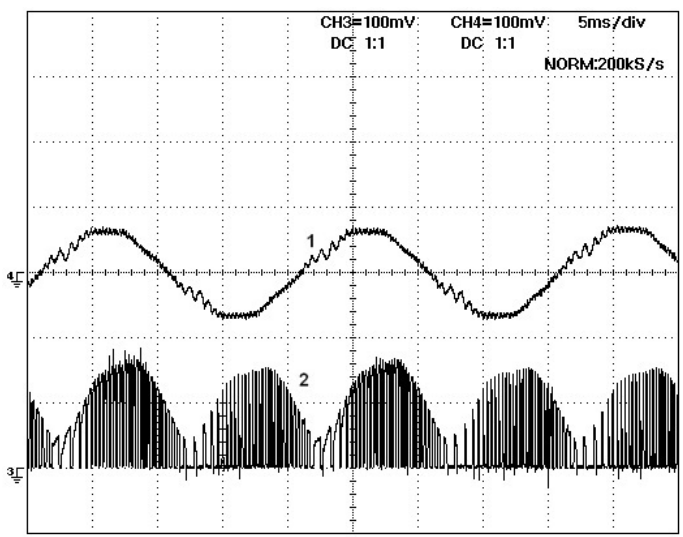

Fig. 11. Experimental result of: 1- input source voltage (50V/Div) and 2 input line current $(1 \mathrm{~A} / \mathrm{Div})$.

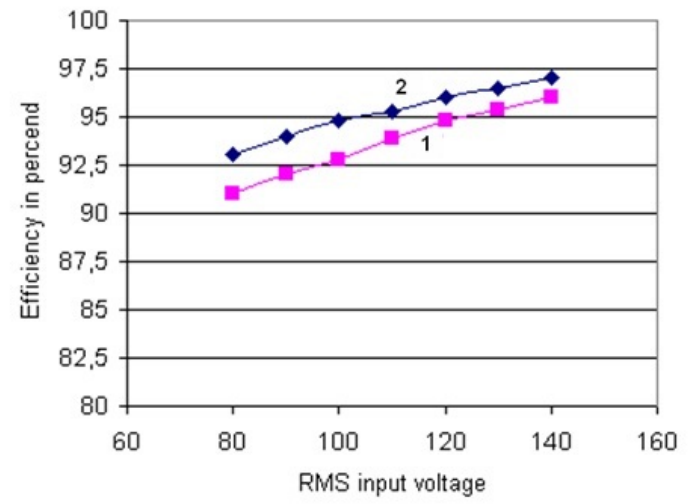

Fig. 12. Comparison of the experimental efficiency results (1- four switches converter, 2- two switches converter).

current THD and displacement. Since the displacement factor is near one, both proposed rectifiers present very high power factors. This high power factor value was obtained even for different duty cycles showing robustness of the control system. For example in [7] the power factor is highly dependent of the duty cycle. At $110 \mathrm{Vrms}$ the power factor of the proposed rectifiers is 0.999 , which is a better result when comparing to other approaches such as [9] and [10]. This also shows the effectiveness of this current control system.

The transient characteristics are investigated showing the response to load step variations, in order to analyze the closed loop performance of the proposed topology. Fig. 14 shows the experimental transient responses of the controller for the step change in the load resistor. This figure shows that it is possible to achieve a fast $(<200 \mathrm{~ms})$ voltage regulation.

\section{CONCLUSIONS}

Two new topologies for single-stage single-phase doublebuck type PFC converters were presented, together with their operation principles. The output voltage wide range, up to twice the peak input voltage, is one of their advantages over the known single-stage Buck rectifiers, whose output voltage is lower than the ac peak value. The proposed double buck topologies present input currents with very low THD. A reduced number of switches on the main current path of the current, leading to relatively high efficiencies are another characteristic of the proposed topologies.

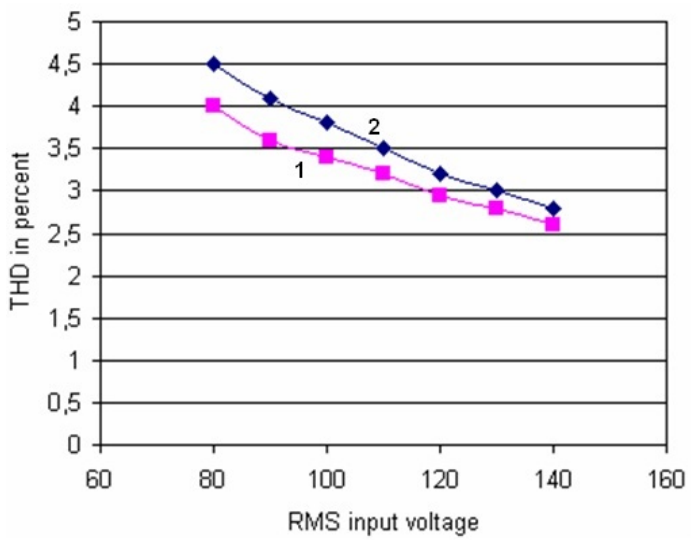

Fig. 13. Comparison of the experimental THD results (1- four switches converter, 2- two switches converter).

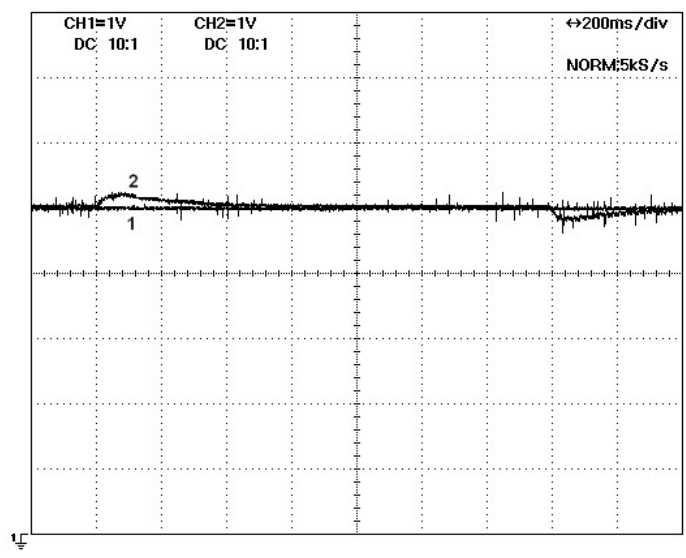

Fig. 14. Experimental results of: 1 - output voltage reference (10V/Div) and 2 - rectifier output voltage(10V/Div).

To control the proposed converters, a separation between fast and slow manifold approach leading to a cascaded controller was considered. For the inner current loop, sliding-mode robust controllers have been designed. For the external voltage loop, a proportional integral controller has been designed and tested. The design of the current and voltage controller parameters has been defined to obtain a high power factor with good output voltage regulation.

Experimental results from a laboratory prototype showed the in phase near sinusoidal input currents, near unity power factors and fast output voltage transient responses. Therefore, these converters are suitable for equipment that must meet stringent power quality standards and widely controllable output voltages.

\section{REFERENCES}

[1] N. Mohan, T. Undeland, and W. Robins, Power Electronics Converters, Applications and Design, John Wiley \& Sons, New York, 1989.

[2] N.-C. Park, H.-S. Mok, and S.-H. Kim, "Reduction of input current harmonics for three phase PWM converter systems under a distorted utility voltage," Journal of Power Electronics, Vol. 10, No. 4, pp. 428433, Jul. 2010.

[3] J. C. Salmon, "Techniques for minimizing the input current distortion of current-controlled single-phase boost rectifiers," IEEE Trans. Power Electron., Vol. 8, No. 4, pp. 509-520, Oct. 1993.

[4] J.-W. Shin, B.-C. Hyeon, and B.-H. Cho, "Digital control of a power factor correction boost rectifier using diode current sensing technique," Journal of Power Electronics, Vol. 9, No. 6, pp. 903-910, Nov. 2009. 
[5] H. Iman-Eini, S. Farhangi, J.-L. Schanen, and M. Khakbazan-Fard, "A fault-tolerant control strategy for cascaded H-bridge multilevel rectifiers," Journal of Power Electronics, Vol. 10, No. 1, pp. 34-42, Jan. 2010.

[6] Y. C. Kim, L. Jin, J. Lee, and J. Choi, "Direct digital control of singlephase AC/DC PWM converter system," Journal of Power Electronics, Vol. 10, No. 5, pp. 518-527, Sep. 2010.

[7] H. Endo, T. Yamashita, and T. Sugiura, "A high-power-factor buck converter," in Proceeding of IEEE_PESC, pp 1071-1076, Toledo, Jun. 1992.

[8] F. P. Souza and I. Barbi, "A Unity power factor buck pre-regulator with feedfoward of the output inductor current," in Proceeding of IEEE_APEC, pp. 1130-1135, Dallas, Mar. 1999.

[9] R. Oruganti and M. Palaniapan, "Inductor Voltage controlled variable power factor buck type AC-DC converter," in Proceeding of IEEE_PESC, pp 230-237, Baveno, Jun. 1996.

[10] V. Grigore and J. Kyyrä, "High power factor rectifier based on buck converter operating in discontinuous capacitor voltage mode," IEEE Trans. Power Electron., Vol. 15, No. 6, pp. 1241-1249, Nov. 2000.

[11] W. Gao and J. Hung, "Variable structure control of nonlinear systems: a new approach," IEEE Trans. Ind. Electron., Vol. 40, No. 1, pp. 45-44, Feb. 1993.

[12] J. F. Silva, "Sliding mode control design of drive and regulation electronics for power converters," Special Issue on Power Electronics of Journal on Circuits, Systems and Computers, Vol. 5, No. 3, pp. 355371, Sep. 1995.

[13] M. Carpita and A. Ricerche, "Sliding mode controlled inverter with switching techniques," EPE Journal, Vol. 4, No. 3, pp. 30-35, Sep, 1994.

[14] V. F. Pires and J. F. Silva, "Three-Phase single-stage four-switch PFC buck-boost type rectifier," IEEE Trans. Ind. Electron., Vol. 52, No. 2, pp. 444-453, Apr. 2005

[15] J. F. Silva, V. F. Pires, Sónia Ferreira Pinto, and J. Dionísio Barros, "Advanced control methods for power electronics systems," Mathematics and Computers in Simulation, Vol. 63, No. 3-5, pp. 281-295, Nov. 2003.

[16] B. Takarics, G. Sziebig, B. Solvang, and P. Korondi, "Multimedia educational material and remote laboratory for sliding mode control measurements," Journal of Power Electronics, Vol. 10, No. 6, pp. 635642, Nov. 2010

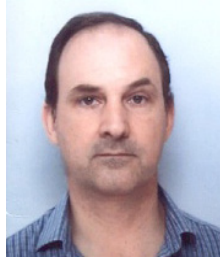

Vitor Fernão Pires was born in Mozambique, in 1962. $\mathrm{He}$ received the B.S. degree in Electrical Engineering from Institute Superior of Engineering of Lisbon, Portugal, in 1988 and the M.S. and Ph.D. Degrees in Electrical and Computer Engineering from Technical University of Lisbon, Portugal, in 1995 and 2000, respectively. Since 1991 he is a member of the teaching staff at Electrical Engineering Department of Superior Technical School of Setúbal - Polytechnic Institute of Setúbal. Presently he is a Professor, teaching Power Electronics and Control of Power Converters. He is also researcher with the Center for Innovation in Electrical and Energy Engineering (Cie3). His present research interests include the areas of power converter topologies, control, modeling and simulation of electrical systems. Dr. Fernão Pires is senior member of the Portuguese Engineering Society and senior member of IEEE.

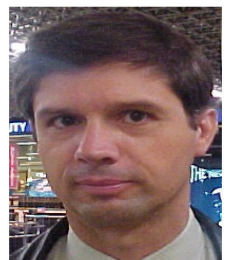

José Fernando Silva was born in Monção Portugal in 1956. He received the Diploma in Electrical Engineering (1980), the Doctor degree in Electrical and Computer Engineering (Power electronics and Control) in 1990, and the Habilitation degree (2002) from Instituto Superior Técnico (IST), Universidade Técnica de Lisboa (TUL), Lisbon, Portugal. He is currently Associate Professor of Power Electronics at IST, teaching Power Electronics and Control of Power Converters, and leader of the group Power Electronics and Power Quality of Center for Innovation in Electrical and Energy Engineering (Cie3). His main research interests include power semiconductor devices, modeling and simulation, new converter topologies, pulsed power, sliding mode and predictive control of power converters and power quality. Dr. Fernando Silva is member of the Portuguese Engineering Society, senior member of IEEE and associated editor of the IEEE Trans. on Industrial Electronics. 